\title{
Sociedade civil e construção democrática: do maniqueísmo essencialista à abordagem relacional
}

MARCELO KUNRATH SILVA*

\section{Introdução}

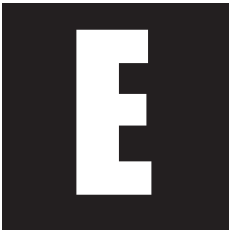

ste artigo $^{1}$ tem como objetivo problematizar um "objeto" pouco abordado quando se analisam as características tradicionais e autoritárias que bloqueiam a construção democrática no Brasil: a "sociedade civil". ${ }^{2}$

Diversos enfoques de análise da construção democrática enfatizam a relação positiva entre organização societária e democratização: seja funcionando como "escolas" de cidadania, seja possibilitando a expressão pública de representações e interesses sociais, seja controlando e orientando a ação estatal, seja desenvolvendo relações de confiança e envolvimento coletivo, as organizações sociais desempenhariam um papel intrinsecamente positivo para a democracia.

A partir do suporte teórico-metodológico da "sociologia relacional" de Norbert Elias e da fundamentação empírica fornecida pela análise comparativa das relações entre sociedade civil e governos municipais em duas cida-

\footnotetext{
* Doutor em Sociologia pela UFRGS. Professor do Departamento de Sociologia/PPGS Desenvolvimento Rural/ UFRGS.E-mail: mksilva@ufrgs.br. Brasil.

1 Uma versão preliminar deste artigo foi apresentada no Seminário Temático "Processo decisório e implementação de políticas públicas no Brasil: novos tempos, novas perspectivas de análise", em 2004, durante o $28^{\circ}$ Encontro Anual da ANPOCS.

2 O termo "sociedade civil" é utilizado, no âmbito deste artigo, para apreender o conjunto de organizações sociais, formais e informais, que constitui o "tecido associativo" empiricamente existente em um dado contexto.
} 
des da Região Metropolitana de Porto Alegre, ${ }^{3}$ questiona-se uma apreensão essencialista e unificadora dos atores sociais, que deixa de perceber a sociedade civil como um espaço de diversidade, de relações de poder e de conflitos, no qual se encontram e intervêm atores marcados por diversas orientações e mantendo diferentes relações com a democracia.

\section{Do maniqueísmo essencialista à abordagem relacional}

A partir do início dos anos 80, em ruptura com uma longa tradição do pensamento social e político brasileiro (Sader e Paoli, 1986), pesquisadores e agentes políticos progressivamente irão enfatizar o papel dos atores sociais na reconstrução, sustentação e/ou aprofundamento da democracia no país. Inicialmente sob forte predomínio do debate em torno dos "movimentos sociais", a discussão sobre a centralidade e o protagonismo dos atores sociais passa a ocorrer, já nos anos 90, sob os marcos do conceito de "sociedade civil", ao qual, normativamente, estavam associados diversos significados positivos do ponto de vista da democratização.

Sob este enfoque teórico, que se colocava numa perspectiva crítica ante a abordagem essencialmente político-institucional do processo de "transição" (entendido este como a retomada dos procedimentos e instituições básicos da democracia representativa, especialmente as eleições periódicas, competitivas e livres), a preocupação deslocava-se para a forma como se estavam configurando as relações entre Estado e sociedade, no sentido da ruptura com as tradicionais formas de exclusão e dominação políticas de vastos segmentos da sociedade brasileira. Neste sentido, apoiados numa perspectiva teórica construída pela articulação entre a teoria habermasiana

3 Os municípios analisados são Gravataí e Sapucaia do Sul, durante a gestão 1997-2000. O trabalho empírico desta pesquisa foi realizado dentro do projeto "Evaluation of participatory budgeting initiatives in Brazilian municipalities", coordenado por Gianpaolo Baocchi, Shubham Chaudhuri e Patrick Heller e financiado com recursos do Banco Mundial. Além disto, contou com recursos da Fundação de Amparo à Pesquisa do Estado do Rio Grande do Sul (FAPERGS), através de um Auxílio Recém-Doutor. 
e o debate teórico sobre "sociedade civil", autores como Sérgio Costa (1994, 1997) e Leonardo Avritzer (1994, 1996) vão destacar o papel dos atores da sociedade civil - especialmente os movimentos sociais e as outras formas organizativas que deveriam canalizar para a esfera pública os "problemas societários" que nascem e emergem do mundo da vida - na construção de novas relações com o sistema político-institucional, as quais possibilitariam uma real democratização, na medida em que garantissem que o "fluxo de poder" fosse direcionado da sociedade civil para o Estado e não o inverso, como seria a tradição política autoritária brasileira.

Essa perspectiva, no entanto, tem sido objeto de crescentes críticas que enfatizam o descompasso entre as prescrições normativas e essencialistas do modelo teórico e os atores empíricos que configuram a "sociedade civil" brasileira, a qual seria altamente heterogênea e marcada por diversas características (clientelismo, autoritarismo, baixa densidade associativa, heteronomia ante os atores políticos e governamentais, etc.) que problematizariam tal vinculação natural e direta entre associativismo civil e democratização. ${ }^{4}$

Outro foco de crítica à perspectiva que naturaliza as virtudes democráticas da sociedade civil advém das análises sobre as experiências de novos formatos institucionais (como, por exemplo, os processos de Orçamento Participativo e os Conselhos de Políticas Sociais) que, especialmente nos anos 90, abriram a gestão pública à intervenção dos atores sociais, seja de forma de direta, seja pela mediação de novas formas de representação. Essas experiências, que se vêm expandindo e se vinculam, em certa medida, à perspectiva de que uma efetiva democratização seria dependente da

\footnotetext{
4 Uma crítica veemente à perspectiva da "nova sociedade civil" e, especialmente, ao seu viés normativo encontra-se no artigo de Lavalle (2003). No presente artigo, diferentemente de Lavalle, o objeto de crítica não é a teoria normativa em si, mas o seu emprego como modelo da realidade que, no limite, tende a se sobrepor aos "objetos empíricos", ocultando-os. Por outro lado, no entanto, considera-se que tal perspectiva normativa possui fertilidade analítica ao concentrar o foco de investigação nas relações entre sociedade e sistema político-institucional, possibilitando, assim, uma análise dos processos de construção democrática que vai muito além dos atores e espaços institucionais.
} 
criação de mecanismos e procedimentos institucionais que possibilitem a expressão dos interesses da sociedade civil e o seu processamento e incorporação pelas estruturas político-administrativas, têm sido problematizadas, na medida em que, em grande parte dos casos, não vem conseguindo alterar de forma significativa as estruturas e dinâmicas políticas tradicionais. ${ }^{5}$

No entanto, algumas análises que adotam uma perspectiva crítica em relação às potencialidades democratizantes da "sociedade civil" também apresentam um viés "essencialista", mas de sentido oposto. Ou seja, contra o pressuposto do inerente caráter democrático da sociedade civil, é assumido o pressuposto da sua insignificância ou, em outras versões, da sua influência negativa à democracia. Ou seja, de "pólo da virtude", que encarnaria a positividade e assumiria o protagonismo do processo de construção democrática, a sociedade civil se torna um espaço da reprodução das desigualdades, de tensionamento das instituições democráticas e/ou de esvaziamento da própria política (Kerstenetzky, 2003).

Partindo de pressupostos teórico-metodológicos desenvolvidos pela "sociologia relacional" de Norbert Elias (1994, 1998, 1999), este artigo busca enfrentar algumas limitações observadas nas perspectivas "essencialistas" acima esboçadas, no que se refere às suas capacidades de produzirem interpretações adequadas à complexidade das configurações empiricamente observáveis das relações entre sociedade civil e construção democrática no Brasil.

Um primeiro aspecto problemático das perspectivas "essencialistas" é a sua tendência a uma abordagem não-relacional da sociedade civil. Ou seja, esta tende a ser tomada como um "objeto" com determinadas características intrínsecas, as quais preestabeleceriam uma determinada forma de relação com o Estado, com a política e, assim, com a própria democracia. Essa abordagem resulta numa apreensão reificada da sociedade civil, a qual teria uma "natureza" específica predeterminada.

5 Um balanço crítico sobre as experiências de participação pode ser encontrada em Dagnino (2002). Para uma análise específica da implantação e funcionamento dos Conselhos Municipais de Desenvolvimento Rural, ver Schneider, Silva e Marques (2004). 
A perspectiva de Norbert Elias critica de forma vigorosa o predomínio de abordagens não-relacionais na análise sociológica, cuja força se expressa até mesmo na maneira como construímos nossos conceitos, os quais tendem a ser apresentados de forma substantivada (a sociedade civil ou o Estado, por exemplo). Isto nos induziria a pensar nossos "objetos" como algo que preexiste e que entra posteriormente em relação com outros "objetos", e não como um "objeto" que só existe na relação com outros "objetos", constituindo-se no que é, a partir desta relação. Como salienta Elias (1999:135),

la forzada tendencia de nuestros idiomas a hacernos hablar y pensar como si todos los 'objetos' de nuestra reflexión, incluidos los propios hombres, fuesen en principio meramente objetos, no sólo sin movimiento, sino también sin relaciones, es extremadamente molesta para la compreensión de los entramados humanos que constituyen el objeto de la sociologia.

A adoção de uma perspectiva relacional na análise da sociedade civil possibilita romper com a noção de uma "natureza" preestabelecida e colocaria a necessidade de analisar, em cada configuração empírica específica, como a sociedade civil se constitui na e pela relação com outras dimensões da realidade social em estudo. Isto implicaria em rejeitar a concepção de que existiria uma sociedade civil cujas características já estariam definidas de antemão, mas sim diferentes configurações da sociedade civil, nas quais esta pode assumir características específicas e, até mesmo, contraditórias.

Além da perspectiva não-relacional e, em certa medida, por causa desta perspectiva, as abordagens "essencialistas" também estão marcadas por um viés dicotômico e maniqueísta. Segundo esse viés de análise, a realidade é interpretada a partir de uma visão polarizada (neste caso, contrapondo sociedade civil e sociedade política ou campo político-institucional como blocos unificados e homogêneos), na qual cada um dos pólos encarna a positividade ou a negatividade, que assim são absolutizadas. 
Essa visão unificadora e maniqueísta, assim como a perspectiva nãorelacional, constitui um sério obstáculo à compreensão da diversidade e da complexidade tanto da sociedade civil quanto do campo político-institucional, na medida em que a adoção dessa concepção simplificadora tende a fazer com que se "expurgue" das análises, em geral de forma não consciente, aqueles aspectos ou atores que não correspondem às prescrições dos modelos teóricos.

Um terceiro aspecto problemático nas abordagens "essencialistas" é a tendência a uma apreensão estática, não histórica, de seus "objetos" de análise (no caso, a sociedade civil). Neste ponto, novamente cabe retomar as elaborações teóricas de Norbert Elias e sua ênfase na necessidade de uma abordagem processual para analisar "objetos" que se apresentam empiricamente como constituídos por e constituintes de processos sociais que exigem uma análise diacrônica. Ou seja, somente através dessa perspectiva de análise torna-se possível apreender os processos que forjaram determinadas configurações sociopolíticas, a partir das quais pode-se compreender a sociedade civil, em um momento e em um lugar, na sua especificidade e complexidade.

Buscando afastar-se de perspectivas não-relacionais, dicotômicas, maniqueístas e estáticas, o presente artigo busca sustentar o argumento de que não existe uma relação unívoca entre sociedade civil e construção democrática. Ao contrário, esta relação apresenta diferenciações de acordo com os distintos contextos locais analisados, os quais constituíram, ao longo de suas trajetórias, configurações locais específicas, nas quais e pelas quais se definem as relações entre os atores da sociedade civil e a democratização da gestão pública.

Concretamente, nos casos dos municípios de Gravataí e Sapucaia do Sul, que serão analisados a seguir, o que se observa é que, durante o período 1997-2000, a maioria dos atores da sociedade civil tende a assumir uma posição de obstáculo às iniciativas de democratização da gestão municipal 
(expressa empiricamente, nestes casos, pela introdução do Orçamento Participativo, a partir de 1997, pelo prefeito Daniel Bordignon, do PT, em Gravataí), inserindo-se de maneira ativa na reprodução de estruturas e práticas políticas hierárquicas (exemplificadas especialmente pela gestão de Valmir Martins, do PDT/PMDB, em Sapucaia do Sul).

\section{Caracterizando os ambientes empíricos da pesquisa}

Quadro 1- Informações sobre os municípios de Gravataí e Sapucaia do Sul

\begin{tabular}{|l|c|c|}
\hline & Gravataí & Sapucaia do Sul \\
\hline Ano de instalação do município & 1940 & 1940 \\
Área territorial & $478,3 \mathrm{Km}^{2}$ & $58 \mathrm{Km}^{2}$ \\
Distância de Porto Alegre & $23 \mathrm{Km}$ & $19 \mathrm{Km}$ \\
População residente*** & 238.438 & 124.763 \\
\% de pobres na população municipal** & $16,18 \%$ & $15,91 \%$ \\
$\%$ de indigentes na população municipal** & $6,2 \%$ & $5,97 \%$ \\
PIBpm per capita* & $\mathrm{R} \$ 6.012,00$ & $\mathrm{R} \$ 7.221,00$ \\
Renda per capita média** & $\mathrm{R} \$ 288,59$ & $\mathrm{R} \$ 271,38$ \\
Finanças municipais - & $\mathrm{R} \$ 80.872 .333,59$ & $\mathrm{R} \$ 40.896 .103,59$ \\
Total da receita arrecadada** & $\mathrm{R} \$ 85.777 .760,27$ & $\mathrm{R} \$ 41.582 .725,21$ \\
Finanças municipais - & $\mathrm{R} \$ 5.603 .501,28$ & $\mathrm{R} \$ 3.751 .488,71$ \\
Total da despesa realizada** & & \\
Finanças municipais - & & \\
Total de despesas com investimento** & & \\
\hline
\end{tabular}

* Dados para o ano de 1999.

** Dados para o ano de 2000.

*** Dados para o ano 2001.

Fontes: IBGE, Perfil dos Municípios Brasileiros - Finanças Públicas 1998-2000 (http:// www.ibge.gov.br/financasmunic/index.htm, acessado em 14/06/2006)

IBGE, Perfil dos Municípios Brasileiros - Gestão Pública 2001 (http://www.ibge.gov.br/ munic2001/index.htm, acessado em 14/06/2006)

METROPLAN, Estatísticas da Região Metropolitana de Porto Alegre (http:// www.metroplan.rs.gov.br/mapas_estatisticas/au_rmpa.htm, acessado em 14/06/2006) FUNDAÇÃO DE ECONOMIA E- ESTATÍSTICA Siegfried Emanuel Heuser (FEE). Anuário Estatístico do Rio Grande do Sul - 2001. 


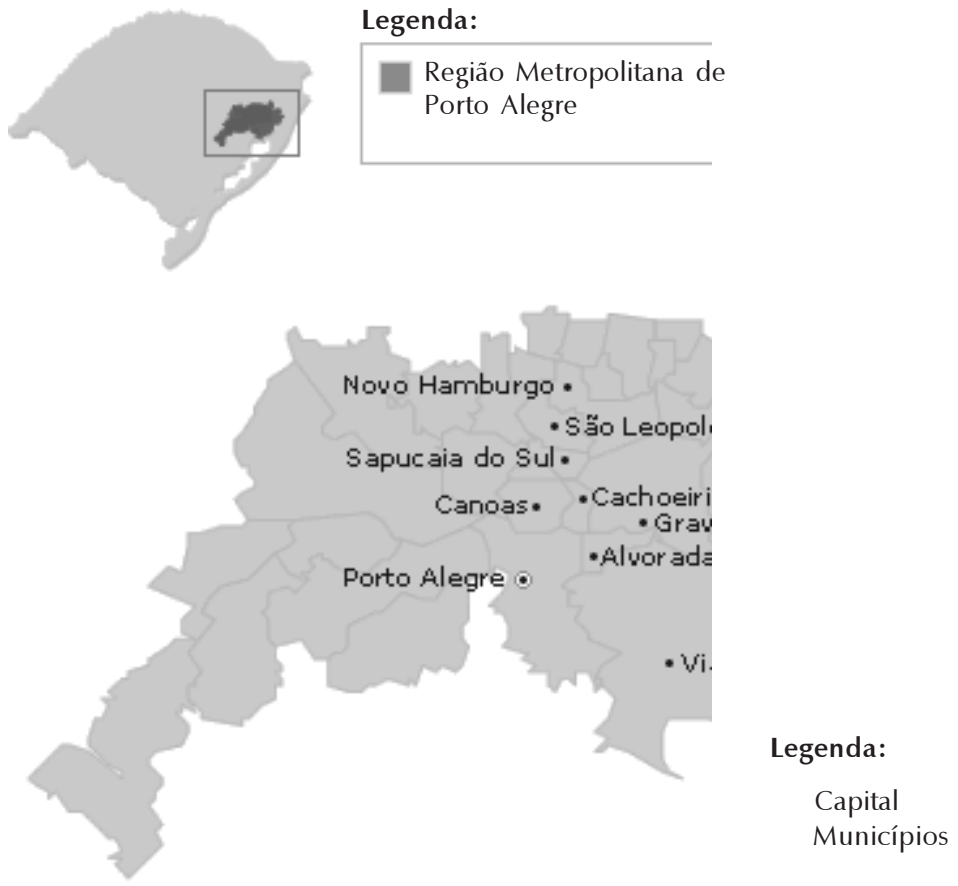

Figura 1- Região Metropolitana de Porto Alegre

Fonte: FUNDAÇÃO DE ECONOMIA E ESTATÍSTICA Siegfried Emanuel Heuser (FEE) http://www.fee.tche.br/sitefee/pt/content/resumo/pg_estado_mapa_3.php (acessado em $14 / 06 / 2006)$

\section{Comparando os casos de Gravataí e Sapucaia do Sul.}

A análise das trajetórias e características dos municípios de Gravataí e Sapucaia do Sul indica similaridades importantes que os qualificam como casos comparáveis para a investigação da relação entre sociedade civil e democratização. 
Em termos das similaridades, podemos observar uma relativa semeIhança do ponto de vista da realidade econômico-social e do contexto sociopolítico no período que antecede à gestão 1997-2000. Os dois municípios têm uma sólida base industrial que oportuniza, através da geração de impostos, recursos significativos para a atuação do governo municipal. Por outro lado, são cidades marcadas por significativos problemas de urbanização, concentrando uma população com profundas carências em termos do acesso à infra-estrutura urbana e com baixos níveis de renda.

Do ponto de vista político, ambos são municípios com elites políticas tradicionais cujas estratégias de reprodução estão centradas fundamentalmente em vínculos particularistas e clientelistas com a população local. No caso de Gravataí, essas práticas são exemplificadas pela atuação do prefeito Mariano Motta (1989-1992), do PDT, que investiu na construção de relações diretas entre o governo municipal e as associações de moradores, as quais foram escolhidas como interlocutores privilegiados do Prefeito em troca de apoio e suporte político. Por outro lado, nos dois casos observamse práticas de criação de entidades a partir de iniciativas governamentais, o favorecimento no atendimento das demandas das entidades que dão suporte ao governante, a doação de recursos ou bens públicos para as entidades alinhadas com o governo e a contratação de "líderes comunitários" para cargos de confiança no governo.

Esse padrão de relações entre sociedade civil e campo políticoinstitucional ofereceu poucas oportunidades para a constituição de formas de organização e atuação mais autônomas e reivindicativas no âmbito da primeira. Ao contrário, as sociedades civis locais encontram-se fortemente subordinadas às elites políticas locais, sendo dependentes especialmente daqueles grupos políticos que estão à frente do governo municipal, com os quais estabelecem relações marcadas por uma significativa assimetria de poder. Os poucos movimentos e organizações sociais que pautaram sua atuação pela busca de relações mais autônomas com o governo municipal, 
tal como associações de moradores originadas do trabalho de base de mediadores religiosos orientados pela Teologia da Libertação ou núcleos locais do Movimento de Luta pela Moradia e da Central dos Movimentos Populares (estes últimos, em Sapucaia do Sul), tenderam a ser excluídos do acesso aos bens e serviços públicos, ocupando, assim, uma posição marginal na dinâmica sociopolítica local.

A dependência e assimetria nas relações entre sociedade civil e campo político-institucional se expressam e, ao mesmo tempo, são reforçadas pela configuração do tecido associativo nos dois municípios. Em ambos os casos, as organizações numericamente predominantes são as associações de moradores e as entidades de prestação de serviços assistenciais, as quais se caracterizam pela intermediação entre população e governo municipal, possuindo, assim, significativa dependência da "boa vontade" governamental para terem acesso aos bens, recursos e/ou serviços públicos que necessitam/demandam. Por outro lado, a presença de movimentos populares orientados para a mobilização e a ação direta, numa lógica de intervenção conflitiva e autônoma, é pouco significativa.

Os sindicatos de trabalhadores, com exceção dos sindicatos de servidores municipais, ${ }^{6}$ em geral são subsedes de sindicatos localizados em outros municípios e têm um papel restrito, fundamentalmente às demandas profissionais, com pouca ou nenhuma incidência na vida política municipal. Os setores empresariais, por seu lado, tendem a incidir na política municipal através de apoios informais a determinados candidatos e do estabelecimento de canais de acesso direto ao Executivo, ${ }^{7}$ buscando a defesa pragmática de seus interesses.

6 O fato de que o sindicato de servidores municipais de Sapucaia do Sul só tenha sido fundado em 2003 indica os obstáculos à organização social neste município.

7 Isto é exemplificado, em Sapucaia do Sul, pela tradição de indicação de um representante do empresariado, através da Associação Comercial e Industrial, para ocupar a Secretaria de Indústria e Comércio. 
Esta configuração das relações entre sociedade civil e campo políticoinstitucional pode ser sintetizada no seguinte esquema:

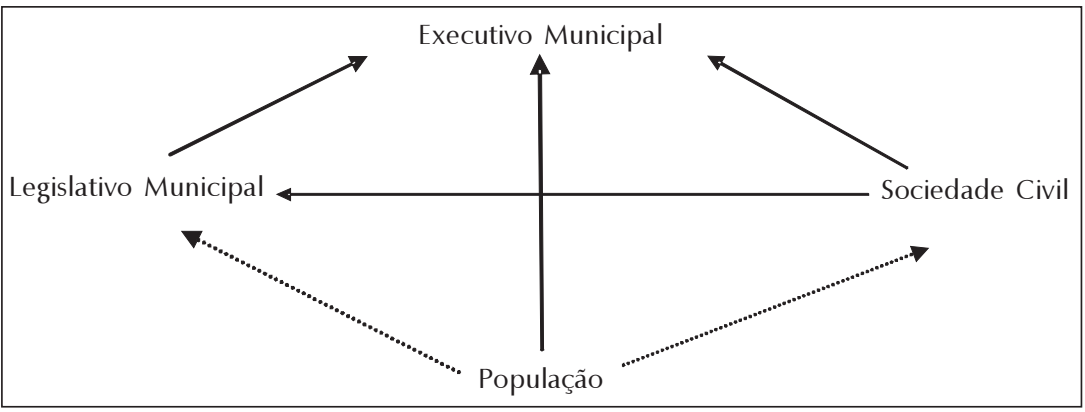

Figura 2 - Configuração sócio-política tradicional dos municípios de Gravataí e Sapucaia do Sul

O que este esquema ${ }^{8}$ indica é a presença de uma configuração sociopolítica caracterizada pela centralidade do Executivo municipal o que, abrindo espaços de atuação privilegiados para determinados atores sociais e políticos, propicia a estes a possibilidade de se constituírem como intermediários entre as demandas da população e os núcleos de decisão e ação do governo municipal. Essa intermediação se constitui, por sua vez, no fundamento do poder e, assim, da reprodução social e política daqueles atores.

Da mesma forma que a relação dos atores sociais e políticos com o Executivo municipal é feita de forma particularista, a relação daqueles com a população também o é. Ou seja, as demandas da população são encaminhadas e, eventualmente, atendidas como demandas particulares, bloqueando-se, assim, a construção de qualquer sentido coletivo ou público entre demandas idênticas, mas que se colocam como concorrentes pelo acesso privilegiado aos bens e serviços públicos.

8 Este esquema se baseia em uma representação gráfica elaborada por Shubham Chaudhuri em uma das reuniões da equipe de pesquisa. 
Em síntese, observa-se uma configuração sociopolítica marcada por relações hierárquicas, clientelistas e particularistas que são reproduzidas pela forma como atuam não apenas os atores políticos e governamentais, mas, também, grande parte dos atores sociais que compõem a sociedade civil "realmente existente" nos dois municípios.

Nos dois casos, é perceptível que a conjuntura política, ao longo da década de 90, é marcada por uma certa instabilidade, com a alteração das forças políticas à frente do governo. Em Gravataí, observa-se a seguinte seqüência na ocupação do governo municipal: Mariano Motta, PDT (19891992); Edir Oliveira, PTB (1993-1996) e Daniel Bordignon, PT (1997-2000). Em Sapucaia do Sul, a seqüência é: Valmir Martins, PDT (1989-1992); Barbosa, PTB (1993-1996) e Valmir Martins, PDT/PMDB (1997-2000). Em ambos os casos, as eleições de 1996 foram polarizadas entre o PT e o PDT. Além disso, os dois prefeitos da gestão 1997-2000 foram reeleitos para a gestão 2001-2004.

Assim, a principal diferença observada na trajetória política dos dois municípios, na década de 90, é que, em Gravataí, ocorre o inédito acesso ao governo das forças políticas de esquerda aglutinadas em torno da candidatura petista, enquanto em Sapucaia do Sul essa alternativa é derrotada pela vitória dos setores políticos tradicionais do município, que, ante a crescente ameaça da candidatura do PT, progressivamente formam uma ampla aliança partidária, na qual se sustenta a candidatura de Valmir Martins à reeleição, em 2000, que derrota novamente a candidatura petista.

Ou seja, de acordo com essa sucinta descrição das trajetórias recentes dos dois municípios, a grande diferença observada é a ascensão de uma nova força política em Gravataí, a partir de 1997, com a eleição do candidato petista, o qual apresenta como uma de suas principais "bandeiras" a busca da democratização da gestão municipal através da introdução de mecanismos de participação social, entre os quais destaca-se o Orçamento 
Participativo (OP). ${ }^{9}$ Qual o impacto desta mudança nas relações tradicionais entre sociedade civil e campo político-institucional, caracterizadas anteriormente? Como os atores sociais se posicionam ante esta experiência de participação social que, hipoteticamente, romperia com aquelas relações hierárquicas, clientelistas e particularistas?

Iniciando uma análise sobre os impactos dessa mudança em Gravataí, em comparação com Sapucaia do Sul, pode-se perceber que a introdução do OP alterou significativamente a relação entre a população e o governo municipal. O OP institui um canal formal de relacionamento entre sociedade e governo, com regras definidas e divulgadas publicamente (mesmo que tenham diversos pontos "obscuros"), que rompe com o atendimento personalizado e casuístico de demandas pontuais, a base sobre a qual se reproduzem as práticas clientelistas, marcantes no caso de Sapucaia do Sul. Tal mudança pode ser expressa no seguinte esquema:

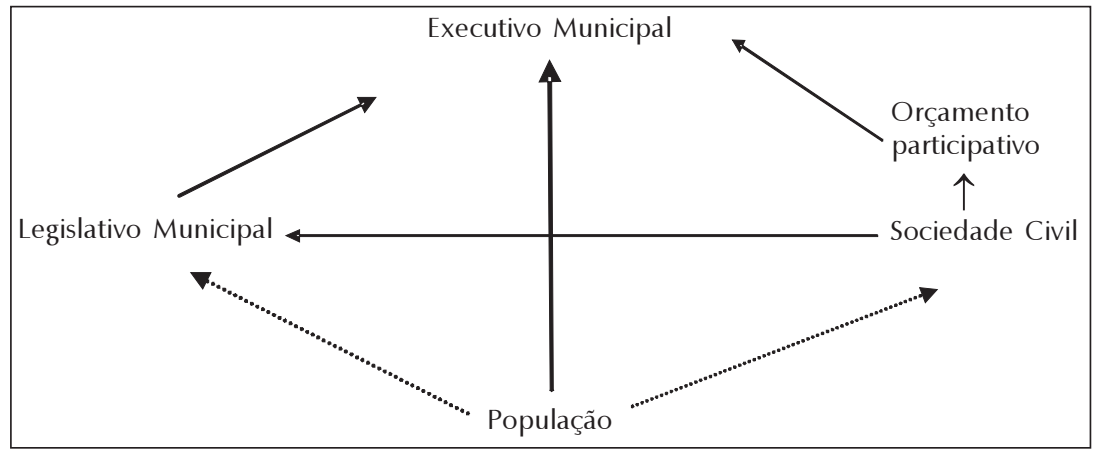

Figura 3 - Nova configuração sócio-política tradicional no município de Gravataí (1997-2000)

9 Um elemento fundamental na sustentação da candidatura petista em Gravataí era o "êxito" da gestão do PT em Porto Alegre (cuja imagem centrava-se, em grande medida, na experiência do OP), que já se encontrava no segundo mandato e, de acordo com todos os prognósticos do período, seria reeleita no pleito de 1996 (como, de fato, foi). 
Essa mudança altera toda a dinâmica política local, ao modificar as fontes de poder dos atores políticos e sociais, especialmente os vereadores e os "líderes comunitários". Com o OP, estes tendem a perder um elemento central da sua reprodução política - a intermediação das demandas sociais através do acesso privilegiado aos centros de decisão governamental -, uma vez que as demandas sociais passam a contar com um espaço formal de apresentação e processamento, o qual, na medida em que se mostra eficaz, passa a ser privilegiado pela população.

No caso de Sapucaia do Sul, ao contrário, mantém-se, na gestão 19972000, o padrão tradicional de relacionamento entre a população, os atores sociais e políticos e o Executivo municipal, ilustrado pela Figura 2. E significativamente, nesse caso, a introdução de um canal de "participação social" (o processo de "consulta"), ${ }^{10}$ por força do contexto político e de pressões legais, não implicou nenhuma alteração importante em termos de democratização da gestão municipal. Tal fato demonstra os limites da mera "inovação legal-institucional", do ponto de vista da mudança das práticas políticas instituídas, cuja capacidade de sobrevivência e utilização das inovações para sua reprodução é exemplarmente ilustrada em Sapucaia do Sul.

Apesar destas profundas diferenças, observa-se, nos dois casos, a manutenção de uma dinâmica que caracteriza a tradição política brasileira: o relacionamento direto entre população e governantes. Fruto da configuração do sistema político brasileiro no qual os partidos e as organizações sociais tendem a apresentar uma escassa inserção social e, neste sentido, possuem uma baixa capacidade de mobilização e representação, a relação direta da população com o governo (encarnado pelo chefe do Executivo)

10 Nos três primeiros anos de gestão (1997, 1998 e 1999), o prefeito Valmir Martins realizava reuniões com os presidentes de associações de moradores, os quais encaminhavam e negociavam suas demandas de forma pontual, por fora do processo de elaboração do orçamento; em 2000, último ano da sua primeira gestão, por pressão da Lei de Responsabilidade Fiscal, mas também pela conjuntura política estadual (na qual o tema da "participação popular" era um dos principais pontos de conflito, com a contraposição entre a "Consulta Popular", instituída pelo governador Antônio Britto no último ano de seu mandato no governo estadual, e o "Orçamento Participativo", instituído pelo PT em Porto Alegre e defendido como modelo a ser implantado no governo estadual), o prefeito Valmir Martins institui um processo de "consulta" à população para a definição de prioridades. 
instituiu-se como característica estrutural da política brasileira, como exemplifica a longa tradição do populismo. Aparentemente a introdução de mecanismos de participação direta, como o OP, pode contribuir para reproduzir e, até mesmo, reforçar tal característica. E isto se coloca como uma tendência particularmente forte, tal como expressa o esquema acima, em contextos como o de Gravataí, no qual a fragilidade do tecido associativo e a oposição de grande parte das "lideranças comunitárias" à participação no OP fazem com que a participação seja, em grande medida, individualizada, sem que haja atores sociais autônomos com capacidade e interesse de exercerem um papel de mediação e, assim, contrabalançarem o poder governamental. ${ }^{11}$

Em relação direta ao aspecto salientado acima, coloca-se um aspecto aparentemente paradoxal quando comparamos o posicionamento das organizações da sociedade civil nos dois casos. No caso de Gravataí, em face das tensões na relação do governo municipal com a maioria das entidades existentes no município (uma vez que estas se encontravam, em grande medida, controladas pelas forças políticas de oposição ao governo petista), o processo participativo se sustentou num contato direto com a população não organizada, levando as lideranças das entidades a se oporem ao OP, pois este era acusado de enfraquecer suas organizações. Já em Sapucaia do Sul, ao contrário, foi destacado pelos "líderes comunitários" o fato de que o governo privilegiou e aumentou a influência das entidades, na medida em que estas passaram a ter um contato direto com o Prefeito e, em alguns casos, conseguiram, através deste, o atendimento de suas demandas. Assim, paradoxalmente, a partir destas avaliações colhidas na pesquisa, poderíamos concluir que a introdução do OP contribuiu para "fragilizar" a sociedade civil em Gravataí e, ao contrário, a manutenção de práticas clientelistas

11 Esta característica diferencia significativamente a dinâmica de participação no OP de Gravataí daquela observada em Porto Alegre por Abers (2000). Para uma comparação entre a experiência de OP de Porto Alegre e outras três experiências em municípios na Região Metropolitana de Porto Alegre, ver Silva (2001). 
"manteve/fortaleceu" a atuação e a influência das organizações sociais em Sapucaia do Sul.

Este aparente paradoxo torna-se menos surpreendente quando se tem em mente as características da sociedade civil nesses municípios, apresentadas anteriormente. Na medida em que as organizações sociais são, em grande medida, fruto de uma longa trajetória de relações de subordinação e dependência ante as forças políticas tradicionais, torna-se compreensível que a manutenção de um "ambiente" no qual se reproduzem essas relações tenda a alimentar o funcionamento de tais organizações. Por outro lado, a introdução de um mecanismo como o OP, quebrando os processos de intermediação clientelista entre demandas sociais e gestão pública (no qual estavam envolvidos e pelo qual se reproduziam não apenas os atores políticos, mas também diversas lideranças sociais), conforme observado em Gravataí, tende a fragilizar as organizações e "lideranças" estruturalmente inseridas e dependentes daqueles processos de intermediação.

Assim, ao romper com a reprodução dessas estruturas tradicionais, a introdução do OP possibilitou que novos setores da população tivessem a oportunidade de acesso ao governo municipal. Neste aspecto, a dinâmica assumida pelo OP de Gravataí, de um lado, foi extremamente eficiente no sentido de possibilitar a participação de uma população dispersa e com escassa ou nenhuma experiência associativa. A simplificação do processo centrado fundamentalmente na priorização de obras locais e a sua disseminação por praticamente todo o município, transferindo a deliberação sobre as prioridades para as mais de 80 plenárias microrregionais, estimularam e viabilizaram uma ampla participação popular que atingiu mais de 20.000 presenças nas plenárias microrregionais e regionais, nos anos de 1999 e 2000 (o que significa, praticamente, $10 \%$ da população total do município!).

De outro lado, no entanto, este formato de OP centrado basicamente na deliberação de obras, sem entrar na discussão de políticas e progra- 
mas mais gerais do e para o município, tendeu a limitar a participação ao âmbito restrito de ações mais pontuais e imediatas, sem enfocar iniciativas mais estratégicas, que se mantiveram restritas às deliberações do Executivo municipal. ${ }^{12}$ Assim, a característica que se constituiu em um dos atrativos do OP de Gravataí, do ponto de vista da mobilização popular - sua objetividade e dispersão -, torna-se um limitante em termos de sua abrangência e capacidade de incidir sobre as linhas de atuação do governo municipal.

Essa característica do OP de Gravataí alterou profundamente a forma de encaminhamento das demandas dos setores populares para o Governo, diferenciando profundamente este caso do de Sapucaia do Sul, no qual se mantiveram as práticas de demandas individualizadas aos vereadores e governantes. Já no caso dos setores empresariais, as mudanças não foram muito significativas em Gravataí, uma vez que esses setores, por um lado, não são demandantes das obras de infra-estrutura básica que predominam no OP e, por outro, buscaram formas de interlocução direta com o Executivo municipal, que manteve em suas mãos a discussão e definição das ações estratégicas. ${ }^{13}$

Com a introdução do OP, observa-se uma significativa ampliação da possibilidade de controle social em relação à atuação do governo municipal. A definição, através da participação social massiva, de um conjunto de ações a serem executadas, mesmo que não tenha sido publicizada de forma mais intensa através da publicação de um Plano de Obras e/ou Investimentos, conferiu maior transparência às ações do Executivo em Gravataí, que passou a estar sob constante monitoramento dos participantes do processo. Além disto, os próprios vereadores, especialmente da oposição, as-

\footnotetext{
12 Uma característica que expressa esta limitação do foco de intervenção do OP de Gravataí é a ausência, no período 1997 2000, das chamadas Plenárias Temáticas, ou seja, de espaços que articulassem a discussão sobre as políticas setoriais com a apresentação e priorização de demandas sociais.

13 A relação do empresariado de Gravataí com o governo municipal petista evoluiu de uma situação de crítica e desconfiança, durante os primeiros anos da gestão 1997-2000, para uma relação de proximidade e cooperação, cuja marca principal é a participação do ex-presidente da Associação Comercial e Industrial de Gravataí como secretário de desenvolvimento econômico na segunda gestão de Daniel Bordignon (2001-2004).
} 
sumem um papel de "vigilantes" da execução das definições do OP, uma vez que identificar algum atraso ou alteração em relação às deliberações do processo confere argumentos no enfrentamento político municipal.

Já no caso de Sapucaia do Sul, a dinâmica é bastante diferenciada. Uma vez que as negociações entre demandantes da sociedade civil e governo se mantiveram particularizadas, reproduzindo uma forma de relacionamento na qual o atendimento de uma demanda se transforma em um "favorecimento", o espaço de controle social é muito mais limitado. O que se observa é um jogo de pressões individualizadas, envolvendo principalmente vereadores e lideranças comunitárias, cada qual buscando obter respostas positivas do Executivo para seus interesses, sem a existência de qualquer mecanismo mais público de controle social e/ou prestação de contas.

Assim, com base na comparação entre os municípios de Gravataí e Sapucaia do Sul e também levando em conta a trajetória de Gravataí, observa-se, como resultado mais significativo da introdução do OP, a mudança na dinâmica política local no que se refere às formas de relacionamento entre Executivo municipal, atores políticos, sociedade civil e população não organizada. O OP possibilitou a intervenção de setores sociais historicamente excluídos das decisões governamentais, rompendo com dinâmicas clientelistas tradicionais entre Executivo, atores políticos e organizações sociais.

Essas mudanças tensionaram práticas políticas instituídas, com particular destaque para os mecanismos de reprodução das elites políticas locais, centrados fundamentalmente na intermediação de demandas sociais aos centros de decisão e execução governamentais.

A potencialidade desta mudança introduzida pelo OP, do ponto de vista da democratização da política local, no entanto, encontra limites tanto na dinâmica das instituições políticas municipais, quanto na estrutura da sociedade civil. A conjugação entre uma estrutura institucional fortemente concentrada no Executivo municipal (e, mais do que isso, na sua personalização: o Prefeito municipal) e uma sociedade civil fragilizada na 
sua autonomia por uma histórica subordinação aos governantes municipais, tende a fazer com que o OP de Gravataí, pelo menos durante a gestão 1997-2000, não tenha gerado, além de uma significativa mobilização e participação de cunho pragmático, um estímulo organizativo e, assim, um fortalecimento da sociedade civil. O resultado, em vista deste limite, tende a ser uma continuidade da dependência em relação às forças políticas à frente do governo municipal (de quem acaba dependendo, em última instância, "aceitar" ou não a participação e o controle social, uma vez que a sociedade civil não é suficientemente forte para impor essa participação e esse controle) e a incapacidade de uma dinâmica de atuação mais autônoma dos atores sociais.

\section{Conclusões}

Finalizando esta análise, podem ser apontadas algumas conclusões em relação ao foco deste artigo - as relações entre sociedade civil e construção democrática. A partir dos casos analisados, pode-se concluir que a reprodução de estruturas e dinâmicas políticas hierárquicas e personalistas não ocorre apenas pela ação das elites políticas e econômicas, mas também envolve segmentos significativos da sociedade civil. Tanto em Sapucaia do Sul quanto em Gravataí, importante parcela das organizações sociais participou e participa ativamente de relações de clientelismo e subordinação aos agentes políticos dominantes, colocando-se como um dos obstáculos à introdução de inovações institucionais de caráter democrático. Ao contrário, tais inovações tendem a ser vistas como ameaças à reprodução de um campo de relações políticas tradicionais, através do qual essas lideranças sociais se constituíram e atuam, sendo, por isto, objeto de crítica e oposição.

Tal conclusão nos levaria à rejeição da perspectiva que enfatiza o caráter inerentemente democrático da sociedade civil? Isto nos levaria a 
sustentar a visão oposta, que aponta seu caráter de obstáculo à construção democrática? A resposta é, ao mesmo tempo, sim e não.

De um lado, a resposta é "Sim", em relação à defesa da necessidade de uma ruptura com a noção de que existiria uma "natureza" democrática intrínseca marcando a atuação dos atores da sociedade civil. Como afirmado anteriormente e demonstrado empiricamente através dos casos analisados neste artigo, o conceito de sociedade civil delimita um campo heterogêneo de atores sociais, os quais podem apresentar os mais diversos tipos de representações e práticas em relação à democracia (divergindo, geralmente, até mesmo sobre o seu significado). A sociedade civil se caracteriza, assim, tanto pela diversidade quanto pela mudança, fazendo com que não haja uma "natureza" preestabelecida, mas sim um contínuo processo de construção, reprodução e transformação dos atores, a partir das configurações geradas pelo campo de relações que estabelecem. Ou seja, a partir de uma abordagem relacional e processual da sociedade civil, esta pode assumir diferentes características que não podem ser derivadas de um quadro teórico essencialista e/ou normativo previamente definido, mas, sim, devem ser identificadas e analisadas a partir da pesquisa empírica.

Nos casos específicos analisados, observamos a constituição de configurações sociopolíticas muito similares, nas quais e pelas quais foram forjados atores sociais cujas formas predominantes de atuação tendem a conferir um caráter pouco democrático às sociedades civis locais. Produzidos por, e reprodutores de práticas e representações políticas marcadas por características clientelistas, personalistas e hierárquicas, esses atores tendem a posicionar-se contra a introdução de inovações de caráter democrático, uma vez que estas rompem com os mecanismos tradicionais através dos quais obtinham o acesso (limitado e subordinado) a determinados ganhos materiais e/ou simbólicos. Nestes casos, então, não por uma questão de natureza, mas de configurações sociopolíticas constituídas ao longo de uma trajetória 
histórica, a sociedade civil local apresenta-se como um obstáculo à democratização, através da introdução de canais de participação social na gestão pública, tal como proposto pelas forças políticas que assumem o governo municipal em Gravataí, em 1997.

De outro lado, no entanto, nossa resposta é "Não", na medida em que a identificação, nos casos analisados, de uma determinada relação entre sociedade civil e democratização, não autoriza a sua generalização enquanto fundamento empírico para sustentar a posição oposta (na qual a sociedade civil assume um papel de reprodutora de desigualdades e autoritarismos). A mesma abordagem relacional e processual que serve para prevenir contra a naturalização e a homogeneização da visão "idealizadora", serve também para evitar o risco oposto, expresso na visão "condenatória", que também naturaliza e toma como homogêneo o que é dinâmico e diverso.

Especificamente em relação à perspectiva crítica sobre a sociedade civil, é importante um esforço de desnaturalização, pois existe uma antiga e forte tradição que "responsabiliza" os atores sociais brasileiros (vistos como "naturalmente" atrasados, inconscientes, imaturos, irracionais e incapazes de reproduzirem os padrões associativos e as práticas sociopolíticas de outros países tomados como "modelos") pela longa história de autoritarismo no Brasil. A partir da perspectiva configuracional, a explicação para as características autoritárias porventura observadas na atuação dos atores da sociedade civil brasileira não se encontra na "natureza" desses atores, mas sim nas configurações sociopolíticas nas quais e pelas quais eles se constituíram historicamente. Ou seja, o caráter clientelista de grande parte das entidades comunitárias de Gravataí ou de Sapucaia do Sul não se deve a uma característica inerente a elas, a uma "essência", mas, sim, ao campo de relações no qual e pelo qual essas entidades foram forjadas. Neste sentido, outras configurações, constituídas em outras trajetórias históricas, podem abrir oportunidades para a constituição de atores com outras características 
e, mais especificamente, com outra relação com os processos de democratização. ${ }^{14}$

Além disso, mudanças institucionais podem constituir novas relações, abrir novas oportunidades e estimular novas práticas organizativas que alterem, em maior ou menor grau, a configuração da sociedade civil e das suas relações com o campo político- institucional. Quais as possibilidades e alcances de mudanças institucionais ante os constrangimentos da trajetória é um problema central para a atual agenda de pesquisa empírica sobre a construção democrática no Brasil, a ser respondido por novas investigações que, como ponto de partida, recusam qualquer noção essencialista e naturalizadora dos atores sociais e políticos.

\section{Referências}

ABERS, Rebecca. Do clientelismo à cooperação: governos locais, políticas participativas e organização da sociedade civil em Porto Alegre. Cadernos da CIDADE, volume 5, $n^{\circ} 7$, maio. 2000.

AVRITZER, Leonardo (coord.). Sociedade civil e democratização. Belo Horizonte: Del Rey, 1994.

AVRITZER, Leonardo. A moralidade da democracia: ensaios em teoria habermasiana e teoria democrática. São Paulo: Perspectiva; Belo Horizonte: Editora da UFMG, 1996.

COSTA, Sérgio. Esfera pública, redescoberta da sociedade civil e movimentos sociais no Brasil - uma abordagem tentativa. Novos Estudos, São Paulo, no 38 , p.38-52, março. 1994.

COSTA, Sérgio. Movimentos sociais, democratização e a construção de esferas públicas locais. Revista Brasileira de Ciências Sociais, São Paulo, v.12, № 35, p.121-134, outubro.1997.

$14 \mathrm{Na}$ verdade, podem ser observadas diferenças profundas em realidades bastante próximas em termos espaciais. Especifinenhuma superioridade natural dos porto-alegrenses, mas sim pela configuração sócio-política distinta ali observada. Para uma análise comparativa envolvendo o município de Porto Alegre, ver Silva (2001, 2003a e 2003b). 
DAGNINO, Evelina (org.). Sociedade Civil e Espaços Públicos no Brasil. Rio de Janeiro: Paz e Terra, 2002.

ELIAS, Norbert. Sociologia Fundamental. Barcelona: Gedisa, 1999.

ELIAS, Norbert. Envolvimento e alienação. Rio de Janeiro: Bertrand Brasil, 1998.

ELIAS, Norbert. A sociedade dos indivíduos. Rio de Janeiro: Zahar, 1994.

KERSTENETZKY, Celia Lessa. Sobre associativismo, desigualdades e democracia. Revista Brasileira de Ciências Sociais, vol.18, n 53, p.131-142. 2003.

LAVALLE, Adrián Gurza. Sem pena nem glória: o debate sobre a sociedade civil nos anos 1990. Novos Estudos, São Paulo, n 66, p.91-109, julho de 2003.

SADER Eder; PAOLI, Maria Célia. Sobre "classes populares" no pensamento sociológico brasileiro. In: CARDOSO, Ruth C. (org.). A aventura antropológica: teoria e pesquisa. Rio de Janeiro: Paz e Terra, p.39-67. 1986.

SCHNEIDER, Sérgio; SILVA, Marcelo Kunrath; MARQUES, Paulo E. Moruzzi (orgs.). Políticas públicas e participação social no Brasil Rural. Porto Alegre: Editora da UFRGS, 2004.

SILVA, Marcelo Kunrath. A expansão do Orçamento Participativo na Região Metropolitana de Porto Alegre. In: AVRITZER, Leonardo; NAVARRO, Zander. (Org.). A inovação democrática no Brasil: o Orçamento Participativo. São Paulo, p.157185. 2003a.

SILVA, Marcelo Kunrath. Participation by design: the experiences of Alvorada and Gravataí, Rio Grande do Sul, Brazil. In: BAIOCCHI, Gianpaolo. (Org.). Radicals in power: the Workers' Party (PT) and experiments in urban democracy in Brazil.. New York, p.113-130. 2003b.

SILVA, Marcelo Kunrath. Construção da "participação popular": análise comparativa de processos de participação social na discussão pública do orçamento em municípios da Região Metropolitana de Porto Alegre/RS. 2001. Tese (Doutorado em Sociologia) - Instituto de Filosofia e Ciências Humanas, Universidade Federal do Rio Grande do Sul, Porto Alegre. 


\section{Resumo}

Este artigo tem como objetivo problematizar um "objeto" pouco abordado quando se analisam as características tradicionais e autoritárias que bloqueiam a construção democrática no Brasil: a "sociedade civil". A partir do suporte teóricometodológico da "sociologia relacional" de Norbert Elias e da fundamentação empírica fornecida pela análise comparativa das relações entre sociedade civil e governos municipais em duas cidades da Região Metropolitana de Porto Alegre, questiona-se uma apreensão essencialista e unificadora dos atores sociais, que deixa de perceber a sociedade civil como um espaço de diversidade, de relações de poder e de conflitos, no qual se encontram e intervêm atores marcados por diversas orientações e mantendo diferentes relações com a democracia.

Palavras-chave: sociedade civil, sociologia relacional, participação social, democratização.

Recebido: 30/06/06

Aceite final: 21/08/06 